The Ag-Sb phase diagram in [Massalski2] was redrawn from [Hansen]. The phase boundaries of the $\varepsilon$ and $\varepsilon^{\prime}$ phases were mostly undetermined. An $\varepsilon$ to $\varepsilon^{\prime}$ polymorphic transformation was reported at $440\left(\mathrm{Ag}\right.$-rich end) to $449^{\circ} \mathrm{C}$ (Sb-rich end).

The phase boundaries of $\varepsilon$ in Fig. 1 are as determined by [92Fes] by means of DTA and XRD. Diffraction spectra of specimens quenched from above and below the presumed transformation temperature of $\varepsilon$ were identical. Hence, an $\varepsilon^{\prime}$ phase is not shown in Fig. 1.
The liquidus of the cph $\zeta$ phase is adjusted in Fig. 1 so that it can be smoothly extrapolated to $\sim 800^{\circ} \mathrm{C}$ at 0 at. \% Sb (approximate melting point of cph $\mathrm{Ag}$ [930ka]).

\section{Cited References}

92Fes: P. Feschotte, F. Monachon, and P. Durussel, J. Alloys Compounds, 186, L17-L18 (1992).

93Oka: H. Okamoto and T.B. Massalski, to be published in $J$. Phase Equilibria, 14(1993).

\title{
Al-Sb (Aluminum-Antimony)
}

\section{H. Okamoto}

The Al-Sb phase diagram in [Massalski2] was redrawn from [84Mca]. [90Cou] also reported a very similar diagram (not shown). Both [84Mca] and [90Cou] calculated the phase diagram by optimization of thermodynamic and phase boundary data. The calculated phase boundaries of both works are in good agreement with experimental results.

\section{Cited References}

84Mca: A.J. McAlister, Bull. Alloy Phase Diagrams, 5(5), $462-465$ (1984).

90Cou: C.A. Coughanowr, U.R. Kattner, and T.J. Anderson, Calphad, $14,193-202(1990)$.

\section{Au-In (Gold-Indium)}

\section{H. Okamoto}

The $\mathrm{Au}-\mathrm{In}$ phase diagram in [Massalski2] was adopted from [87Oka]. The Au-rich phase boundary of $\zeta$ was unknown, and the existence of the $\alpha_{1}$ phase with a nearly constant width to low temperatures was questioned.

[92Ans] calculated the Au-In phase diagram by optimization of thermodynamic [88Ans] and phase diagram data (same as [87Oka]). The $\zeta$ and $\alpha_{1}$ phase boundaries of the [870ka] diagram are modified in Fig. 1 according to the calculated results. The phase boundaries below the eutectoid decomposition of $\alpha_{1}$ must be confirmed experimentally. Boundaries of other phases have not been modified because [92Ans] assumed no solubility ranges in their model, whereas [87Oka] showed substantial ranges for the $\gamma$ and $\psi$ phases, as shown in Fig. 1 .

\section{Cited References}

87Oka: H. Okamoto and T.B. Massalski, Phase Diagrams of Binary Gold Alloys, H. Okamoto and T.B. Massalski, Ed., ASM International, Metals Park, OH, 142-153(1987).

88Ans: I. Ansara and J.P. Nabot, Thermochim Acta, 129, 89-97 (1988). 92Ans: I. Ansara and J.PNabot, Calphad, 16(1), 13-18(1992).

\section{Be-Nb (Beryllium-Niobium)}

\section{H. Okamoto}

The $\mathrm{Be}-\mathrm{Nb}$ phase diagram in [Massalski2] was redrawn from [87Oka], who added $\mathrm{Be}_{5} \mathrm{Nb}$ to the diagram of [Massalskil] based on the report of this compound by [61Arz] and [63Arz], with confirmation by [68Ray]. In this diagram, the peritectoidal formation of $\mathrm{Be}_{5} \mathrm{Nb}$ and eutectoidal decomposition of $\mathrm{Be}_{17} \mathrm{Nb}_{2}$ were shown at 1485 and $1415^{\circ} \mathrm{C}$, respectively, ac- 